\title{
A Male Patient Presenting with Major Clinical Symptoms of Glucocorticoid Deficiency and Skeletal Dysplasia, showing a Steroid Pattern Compatible with $17 \alpha$-Hydroxylase/ 17,20-Lyase Deficiency, but without Obvious CYP17 Gene Mutations
}

\author{
Masanori ADACHI, Katsuhiko TACHibANA, Yumi ASAKURA, Seizo SUWA, and Gen NiShimURA* \\ Department of Endocrinology and Metabolism, Kanagawa Children's Medical Center, Yokohama 233-8555, Japan \\ * Department of Radiology, Dokkyo University School of Medicine, Tochigi 321-0293, Japan
}

\begin{abstract}
We report the case of a 17-year-old boy with delayed puberty, who presented a complexity of clinical problems. An analysis of steroid hormones led to a diagnosis of $17 \alpha$-hydroxylase/17,20-lyase deficiency (17OHD). Unlike typical cases of $17 \mathrm{OHD}$, however, the patient had pubertal development without medical intervention. In addition, he never exhibited the symptoms of mineralocorticoid excess, showing instead the symptoms of glucocorticoid deficiency, including fatigability, emaciation, and weight-loss induced by minor infection. He also had dysmorphic features, which comprised marfanoid habitus, arachnodactyly and putative craniosynostosis. The combination of these malformations substantially resembled that of Shprintzen-Goldberg syndrome. Direct sequencing of the CYP17 gene did not reveal any significant aberrations in the exons or exon-intron boundaries. We speculate that the association of partial combined 17OHD with the Shprintzen-Goldberg phenotype in the present patient may result from an aberration of a hitherto unknown gene that controls both steroid hormone synthesis and skeletal development.
\end{abstract}

Key words: $17 \alpha$-hydroxylase/17,20-lyase deficiency, Adrenal failure, Shprintzen-Goldberg syndrome, CYP17

(Endocrine Journal 46: 285-292, 1999)

\begin{abstract}
A SINGLE polypeptide, $\mathrm{P} 450 \mathrm{c} 17 \alpha$, encoded by a single copy gene (CYP17) located on chromosome 10q2425 , catalyzes both $17 \alpha$-hydroxylation and 17,20-lyase reactions in steroid biosynthesis in the gonads and the adrenal cortex [1]. Total impairment of P450c17 $\alpha$ function, namely, complete $17 \alpha$-hydroxylase/17,20-lyase deficiency (complete 17OHD), leads to the symptoms of mineralocorticoid (MC) excess combined with those of sex steroid deficiency $[1,2]$. Overproduction of MC, particularly of 11-
\end{abstract}

Received: September 10, 1998

Accepted: January 13, 1999

Correspondence to: Dr. Masanori ADACHI, Department of Endocrinology and Metabolism, Kanagawa Children's Medical Center, Mutsukawa 2-138-4, Minami-ku, Yokohama 232-8555, Japan deoxycorticosterone (DOC), causes hypertension and hypokalemia. Affected females $(46, \mathrm{XX})$ usually present with absence of sexual development or primary amenorrhea, while affected males $(46, \mathrm{XY})$ manifest either female external genitalia or ambiguous genitalia. In addition to many reports of complete 17OHD, there have been several case reports of partial 17OHD, which is characterized by modestly conserved sex steroid synthesis, along with the presence of menstruation, if not regular, in females and muscularization to some degree in males [3-5]. Hypertension and hypokalemia are cardinal features in partial $17 \mathrm{OHD}$, as in the complete form. We report here a male $(46, \mathrm{XY})$, whose endocrinological manifestations were those of partial combined 17OHD with spontaneous pubertal development, but who had unusual clinical manifestations, comprising 
the symptoms of glucocorticoid deficiency and generalized skeletal dysplasia. Molecular analysis of the $C Y P 17$ gene did not reveal any mutation of the gene. The pathogenesis of this patient's unusual combination of abnormalities is discussed.

\section{Case report}

A 17-year-old Japanese boy was examined because of general fatigue, susceptibility to infection, and emaciation. He was born to healthy, non-consanguineous parents. Two younger brothers were healthy. The family history was not noteworthy. The patient was reported to be unremarkable in the perinatal period, except for bilateral cryptoorchidism. He showed normal psychomotor development: he spoke a few comprehensive words at 9 months of age and walked without support at 15 months. He underwent bilateral orchidopexy at 6 years of age. At that time, he was noted to have an inconspicuous penis, which led to the first endocrinological evaluation. Neither hypertension $(92 / 62 \mathrm{mmHg}$ ) nor hypokalemia (serum $\mathrm{K}=5.0$ $\mathrm{mEq} / \mathrm{l}$ ) was evident. The serum cortisol level in the early morning was adequate $(14.8 \mu \mathrm{g} / \mathrm{dl})$. Testosterone response to exogenous hCG (testosterone $32.9 \mathrm{ng} / \mathrm{dl}$ after hCG $3,000 \mathrm{IU} / \mathrm{m}^{2} \mathrm{i} . \mathrm{m} .3$ days) was inappropriate, so that hypogonadism was diagnosed. Thereafter, a gradual decline in the patient's growth rate led to the second endocrinological study at 13 years of age. At that time, the patient's height was $142.5 \mathrm{~cm}(-1.9 \mathrm{SD})$, and his weight was $27.5 \mathrm{~kg}$. Blunted testosterone response to hCG (testosterone $34.0 \mathrm{ng} / \mathrm{dl}$ after hCG 3,000 IU i.m. 3 days) associated with normal gonadotropin levels (LH 3.5 IU/1, FSH $2.4 \mathrm{IU} / \mathrm{l})$ was found. Although $\mathrm{GH}$ secretion was not impaired, recombinant $\mathrm{GH}$ therapy was attempted. After a few months of $\mathrm{GH}$ administration, the patient showed commencement of pubertal development and an increased growth rate. At 16 years of age, he exhibited emaciation, general fatigue, and unusual weight-loss related to episodes of minor infection. Withdrawal from GH therapy at 17 years of age did not ameliorate these symptoms. On admission, the patient's height was $163.6 \mathrm{~cm}(-1.2 \mathrm{SD})$, weight $36.5 \mathrm{~kg}$, head circumference $51 \mathrm{~cm}(-3.8 \mathrm{SD})$, and arm span $170.0 \mathrm{~cm}$. He was normotensive $(122 / 68 \mathrm{mmHg})$, and presented normal adult external genitalia with each testis having a volume of $12 \mathrm{ml}$ (Prader's orchidometer). Pubic hair was graded as Tanner 4, whereas axillary hair was Tanner 3. Gynecomastia was absent. He showed abnormal facies (Fig. 1), along with arachnodactyly, clubfeet, contracture of bilateral toes (3rd-5th), and restricted flexion in the DIP joints of the hands. $\mathrm{He}$ had neither ectopia lentis nor cardiac murmur. Chromosome analysis showed a normal karyotype, $46, \mathrm{XY}$. Serum electrolyte concentrations (Na 141 $\mathrm{mEq} / \mathrm{l}, \mathrm{K} 3.9 \mathrm{mEq} / \mathrm{l}$ ) were normal. Other routine laboratory findings were unremarkable. Endocrinological evaluation yielded the following results: first, circulating levels of 17-deoxysteroids (pregnenolone, progesterone, DOC, 18OH-DOC and corticosterone) were apparently high both before and after rapid ACTH stimulation, whereas those of cortisol, dehydroepiandrosterone (DHEA) and androstenedione were low for his age (Table); second, the cortisol level failed to respond to $\mathrm{CRH}$ loading despite its sufficient basal concentration, whereas ACTH showed an exaggerated response to $\mathrm{CRH}$ loading (Fig. 2). The

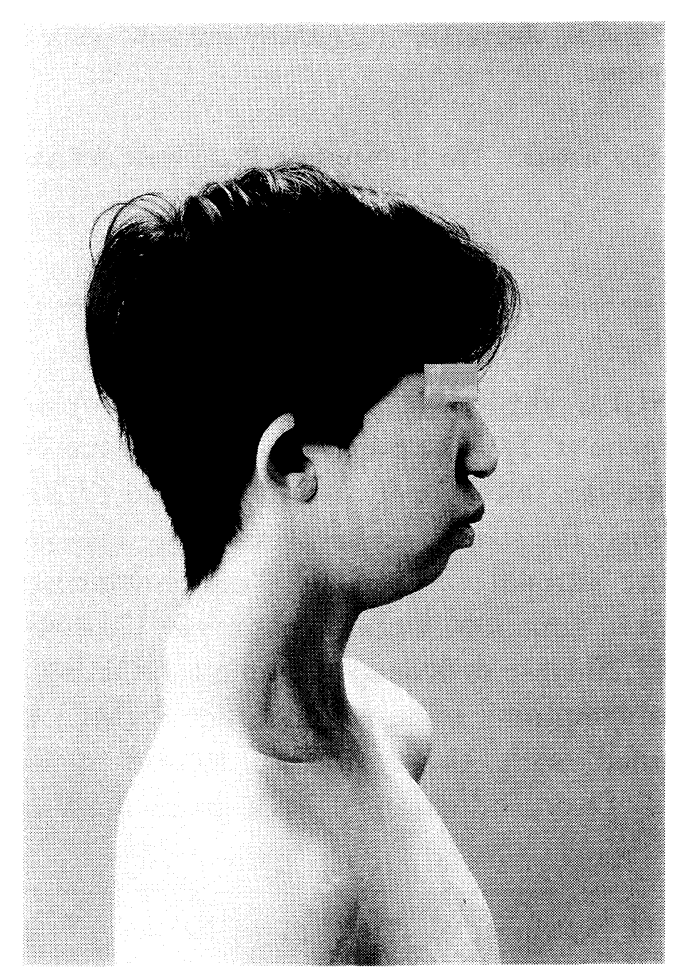

Fig. 1. A photograph of the patient at 17 years of age showing malformed, small, and low-set ear and large nose. In addition, he exhibited wide palpebral fissure and hypotelorism, which are not shown in this figure. 
Table 1. Serum steroid levels before and after rapid ACTH stimulation*

\begin{tabular}{|c|c|c|c|c|}
\hline & baseline value & (reference range**) & $\begin{array}{c}60 \text { min. after ACTH } \\
\text { stimulation }\end{array}$ & $\left(\right.$ reference range $\left.{ }^{* *}\right)$ \\
\hline pregnenolone (ng/ml) & 2.28 & $(0.1-0.3)$ & 3.87 & \\
\hline progesterone (ng/ml) & 16.10 & $(0.1-0.3)$ & 46.30 & \\
\hline $\mathrm{DOC}(\mathrm{ng} / \mathrm{ml})$ & 0.67 & $(0.05-0.14)$ & 1.17 & $(0.19-0.46)$ \\
\hline corticosterone $(\mathrm{ng} / \mathrm{ml})$ & 22.2 & $(1.0-5.0)$ & 69.5 & $(1.5-20.0)$ \\
\hline $18 \mathrm{OH}-\mathrm{DOC}(\mathrm{ng} / \mathrm{ml})$ & 0.91 & $(0-0.10)$ & NT & \\
\hline aldosterone (ng/dl) & 19.0 & $(4-12)$ & NT & \\
\hline $17 \mathrm{OH}$-pregnenolone $(\mathrm{ng} / \mathrm{ml})$ & 8.91 & $(0.32-2.97)$ & 10.70 & $(2.20-8.59)$ \\
\hline $17 \mathrm{OHP}(\mathrm{ng} / \mathrm{ml})$ & 22.2 & $(0.51-1.90)$ & 39.1 & $(1.05-2.30)$ \\
\hline $11 \mathrm{DOF}(\mathrm{ng} / \mathrm{ml})$ & 0.98 & $(0.14-1.15)$ & 1.76 & $(0.87-2.07)$ \\
\hline cortisol $(\mu \mathrm{g} / \mathrm{dl})$ & 9.7 & $(5.0-15.0)$ & 12.1 & $(18.0-27.0)$ \\
\hline DHEA (ng/ml) & 1.41 & $(1.02-4.01)$ & 2.06 & $(1.93-5.09)$ \\
\hline androstenedione $(\mathrm{ng} / \mathrm{ml})$ & 0.52 & $(0.57-1.51)$ & 0.73 & $(0.78-2.15)$ \\
\hline testosterone $(\mathrm{ng} / \mathrm{dl})$ & 298 & $(278-702)$ & NT & \\
\hline
\end{tabular}

* $250 \mu \mathrm{g}$ of ACTH (Cortrosyn) was infused intravenously at 9:00 a.m. Blood samples were drawn via an indwelling venous catheter before and $60 \mathrm{~min}$. after the injection. Each steroid, except 17OHP, was measured by specific RIA with (pregnenolone, DOC, corticosterone, 18OH-DOC, 17OH-pregnenolone, 11DOF, androstenedione) or without (progesterone, aldosterone, cortisol, DHEA, testosterone) extraction. 17OHP was measured by EIA.

** The reference range was adopted from data reported by Lashansky G et al. (1991, J Clin Endocrinol Metab 73: 674-686), Peterson RE et al. (1985, $N$ Engl J Med 313: 1182-1191) and Kater CE et al. (1994, Endocrinol Metab Clin North Am 23: 341-357)

17OHP: 17-hydroxyprogesterone; 11DOF: 11-deoxycortisol; NT: not tested
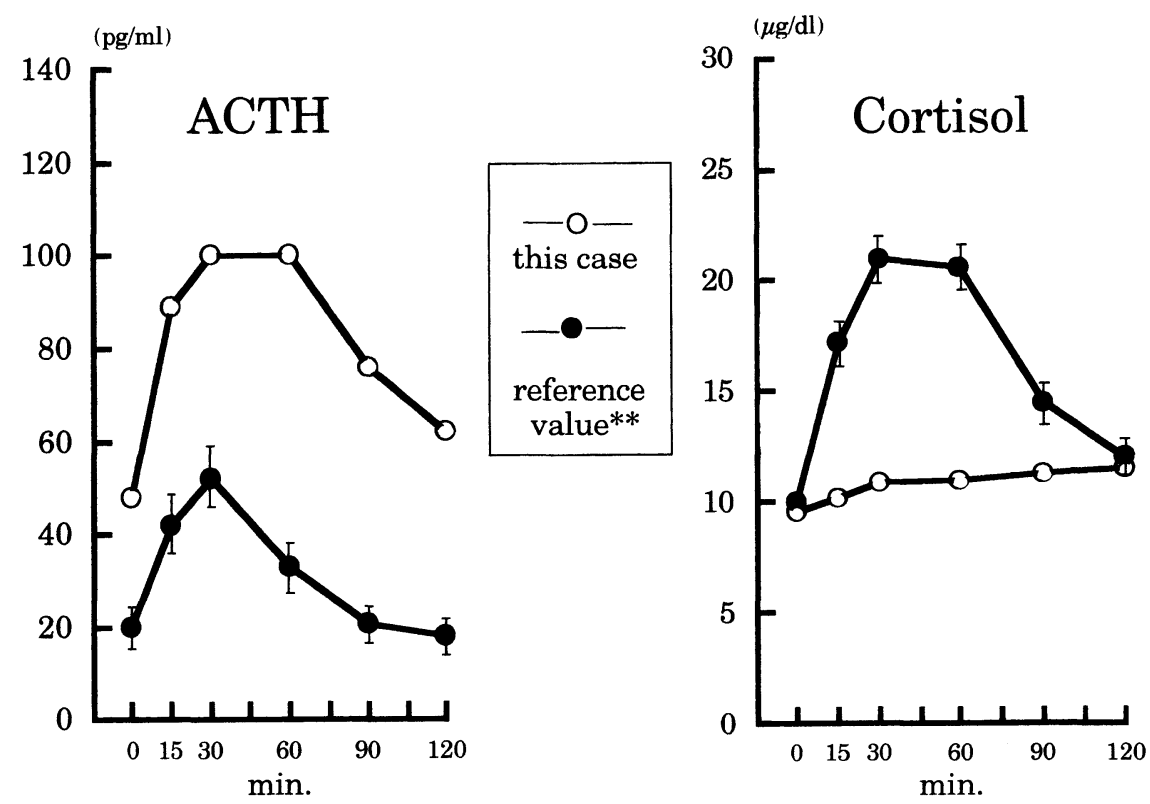

Fig. 2. ACTH and cortisol responses to $\mathrm{CRH}$ stimulation*

${ }^{*}$ Human $\mathrm{CRH}$ of $2 \mu \mathrm{g} / \mathrm{kg}$ was infused intravenously at $8: 00$ a.m. Blood samples were drawn via indwelling venous catheter. Plasma ACTH concentration was measured by specific RIA.

** Reference value was adopted from data in children of non-endocrine short stature reported by Tanaka T et al. (1993, Endocrine J 40: 581-589) Vertical lines denote mean +/- SEM. 
a

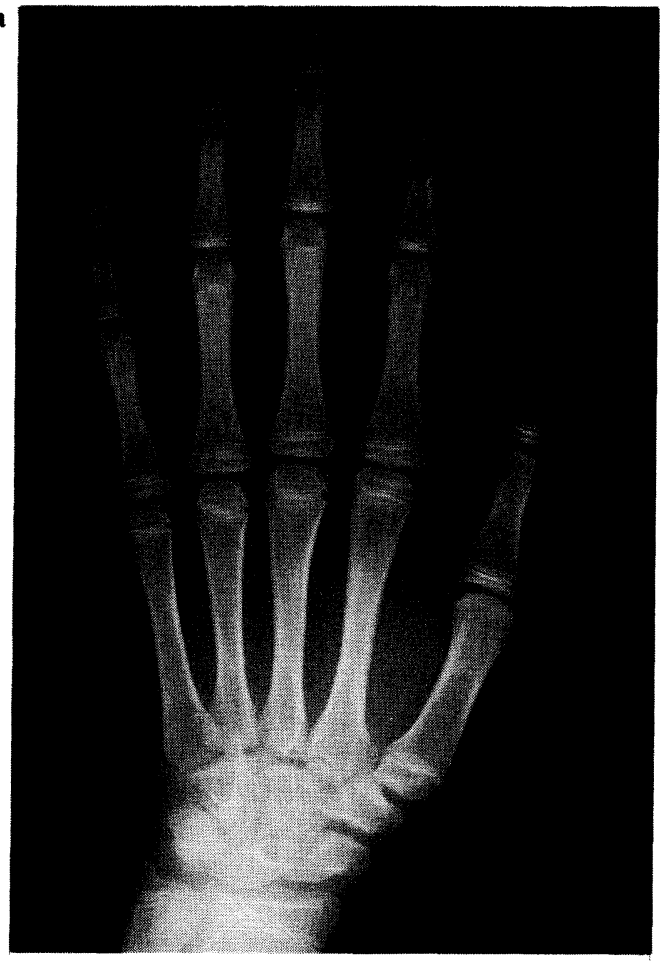

c

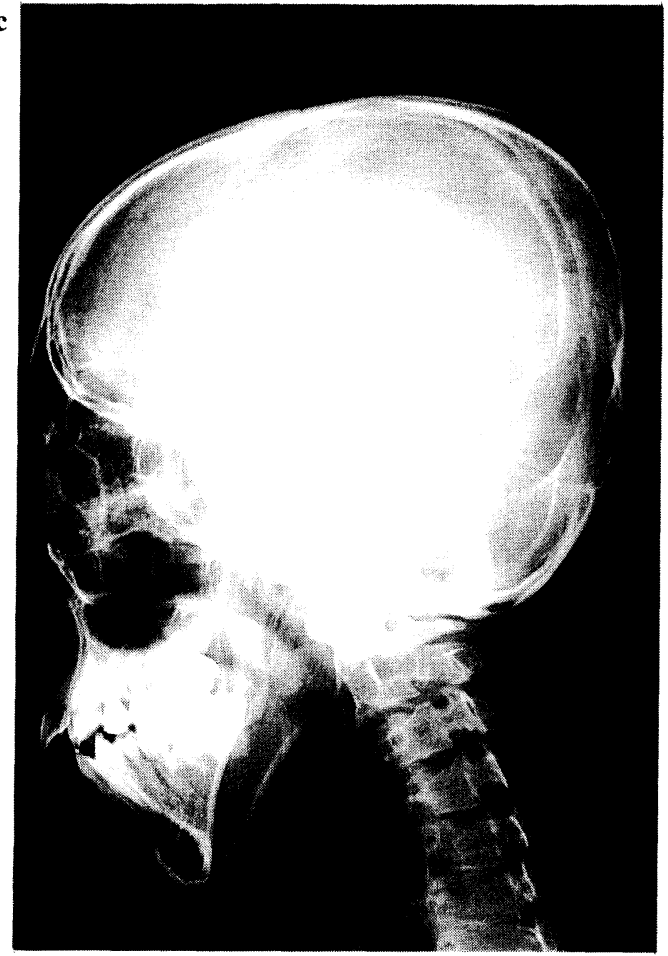

b

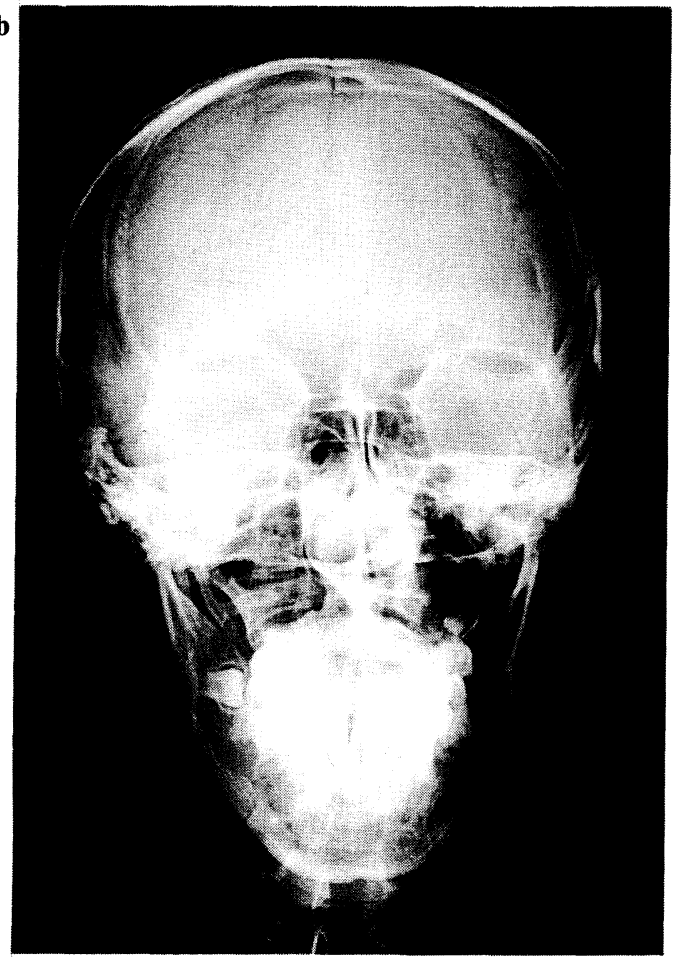

d

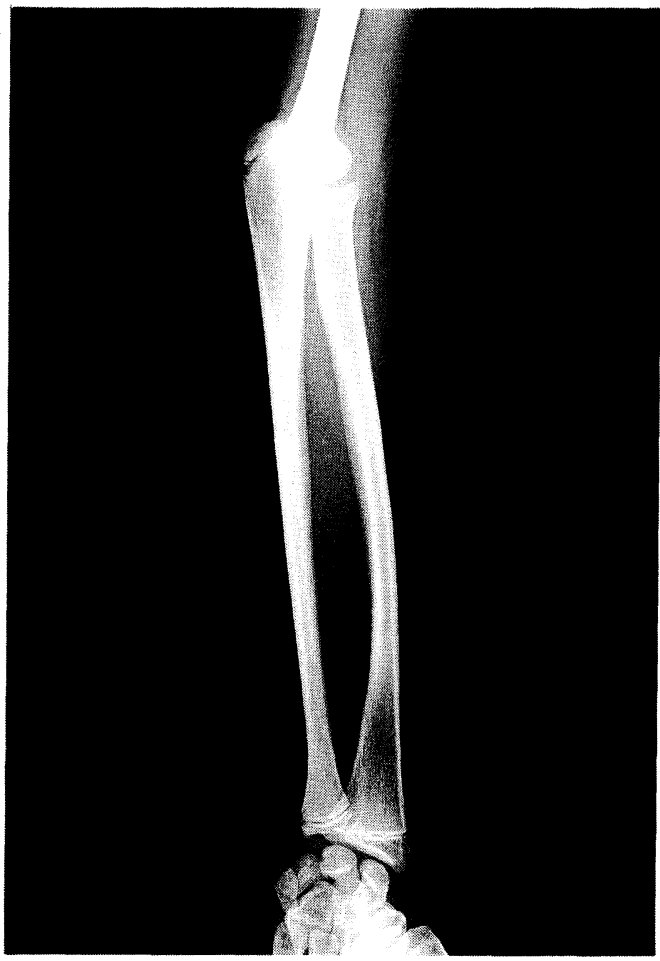

Fig. 3. a-d: Skeletal radiographs at 17 years of age

a) arachnodactyly with mild undertubulation of the short tubular bones

b, c) Craniosynostosis was suspected because of shortening of the anterior cranial fossae and invisibility of the coronal sutures.

d) bowing of the radius and radial head deformity 
diurnal variation in the cortisol level was not impaired (cortisol at $0 \mathrm{AM}: 2.7 \mu \mathrm{g} / \mathrm{dl}$ ); third, $\mathrm{LH}$ and FSH were very high $(58.3 \mathrm{IU} / 1,62.4 \mathrm{IU} / 1$, respectively) despite a lower-than-normal level of testosterone. The aldosterone level was also high, but plasma renin activity (PRA) was normal $(1.7 \mathrm{ng} / \mathrm{ml} / \mathrm{hr})$. Urinary 17-deoxysteroid metabolites were increased (data not shown) whereas daily urinary free cortisol was lower normal $(32.2 \mu \mathrm{g} / 24 \mathrm{hr})$. Consequently, partial combined 17OHD was diagnosed. Radiographic examination (Fig. 3) showed generalized skeletal changes, consisting of arachnodactyly with undermodeling of the short tubular bones and joint deformities. A mild degree of craniosynostosis was highly suspected because of shortening of the skull base, although the cranial sutures were not completely obliterated. These skeletal abnormalities, together with the patient's dysmorphic features, led to a diagnosis of Shprintzen-Goldberg syndrome (marfanoid craniosynostosis syndrome).

\section{Method}

Genomic DNA was prepared from white blood cells by standard techniques. The exons and exonintron boundaries of the $C Y P 17$ gene were amplified by polymerase chain reaction (PCR) with oligonucleotide primers, as reported by Monno et al. [6] Each PCR with a Perkin-Elmer/Cetus Thermal Cycler (Perkin-Elmer, Norwalk, CT) was performed as follows: 40 cycles of 15 seconds at $96^{\circ} \mathrm{C}, 30$ seconds at $55^{\circ} \mathrm{C}$ and 90 seconds at $72^{\circ} \mathrm{C}$. PCR products were resolved by $1.5 \%$ agarose gel electrophoresis and directly sequenced using an automated DNA sequencer (Applied Biosystems, Inc., Foster City, CA) with Taq DyeDeoxy sequencing reagents (Applied Biosystems, Inc.).

\section{Results}

No hitherto reported mutations, including nucleotide substitution, splicing mutation, small insertion and small deletion, and novel mutation, were identified in the coding regions or the exon-intron boundaries (according to the CYPI7 sequence data reported by Picado-Leonard et al. [7] and by Kagimoto et al. [8]).

\section{Discussion}

The high 17-deoxysteroid levels in the serum and urine of the present patient, with the poor cortisol response to the exogenous ACTH and CRH as well as the lower daily urinary free cortisol level, indicated that $17 \alpha$-hydroxylation reaction in his adrenal cortex was disturbed. On the other hand, the existence of androgen synthetic defect in his adrenal gland and testis was demonstrated by impaired responses of DHEA and androstenedione to the rapid ACTH test and by high gonadotropin levels, respectively. Accordingly, we diagnosed this boy as having combined 17OHD. Since his testosterone production was conserved to such an extent that he experienced spontaneous puberty, a more precise diagnosis would be partial combined 17OHD. His growth delay, which is uncommon in $17 \mathrm{OHD}$, may be attributable to the accompaniment of the skeletal dysplasia discussed later.

Regarding the hormonal data described above, some unusual issues exist. First, moderately high 17-hydroxyprogesterone (17OHP) and 17OH-pregnenolone levels may be reminiscent of the report of multiple defects in steroid-biosynthesis by Peterson et al. [9], namely, combined deficiencies of $17 \alpha$ hydroxylase, 17,20-lyase and 21-hydroxylase. Anecdotal description of similar examples was also reported $[10,11]$. These reported cases of multiple defects closely resemble those in our patient in not only basal $17 \mathrm{OHP}$ and $17 \mathrm{OH}$-pregnenolone values but also their unexaggerated responses to ACTH. In addition, two 46,XY cases among them presented with incomplete male pseudohermaphroditism as in our patient. This particular combination may derive from a defect in the membrane-bound flavoprotein termed $\mathrm{P} 450$ reductase, which provides electrons to all these microsomal enzymes [12]. But since direct evidence of it is lacking, we assume that recognition of this combination as a distinct clinical entity should await deliberate discussion. On the other hand, it may be possible that at least some of the circulating $17 \alpha$-hydroxylated intermediates in such patients were produced in gonads under stimulation with high levels of gonadotropins. In fact, three months of dexamethasone administration $(0.5 \mathrm{mg}$ a day) to our patient had failed to suppress $17 \mathrm{OHP}(11.5 \mathrm{ng} / \mathrm{ml})$ and $17 \mathrm{OH}$-pregnenolone $(2.64 \mathrm{ng} / \mathrm{ml})$ to below the 
normal range, but his ACTH level had been below the detection limit at that time. The validity of the association of 21-hydroxylase deficiency in our patient therefore needs further investigation.

The second unusual aspect in our patient is the normal basal cortisol level, despite the impaired response to ACTH and CRH. Since his circulating cortisol level declined to $2.7 \mu \mathrm{g} / \mathrm{dl}$ at midnight, interference of other intermediates in the radioimmunoassay system seems unlikely, and this can also be further supported by the lower, but normal urinary free cortisol level. We infer that his basal cortisol level had been kept just at lower normal at the expense of over-secretion of $\mathrm{ACTH}$, and this condition could result because the $17 \alpha$-hydroxylase defect was partial.

A feature of our patient was the conspicuous symptoms of GC deficiency instead of those of MC excess. 17OHD does not usually manifest as GC insufficiency, despite impaired cortisol synthesis. A search of the literature confirmed only 3 reported cases of 17OHD with manifestations of GC insufficiency, such as hypoglycemia and emaciation [13-15]. This paradox has been attributed to enhanced production of corticosterone (so called "back up" GC), which is mainly secreted from the zona fasciculata through increased ACTH stimulation.

In patients with $17 \mathrm{OHD}$, corticosterone is usually 50 - to 100 -fold the normal range and is sufficient to provide adequate GC activity. However, corticosterone in our patient $(22.2 \mathrm{ng} / \mathrm{ml})$ was lower than that of previously reported cases $(40-300 \mathrm{ng} / \mathrm{ml})$ [2], which accounts for the conspicuous symptoms of GC deficiency and ultimately the paucity of "back up" GC in our patient. This lower corticosterone level must be the result of somewhat conserved $17 \alpha$-hydroxylase activity. That is to say, since the impairment of $17 \alpha$-hydroxylase is not complete, ACTH-dependent production of corticosterone in the adrenal cortex should be limited in our patient. Lower DOC $(0.67 \mathrm{ng} / \mathrm{ml})$ and higher aldosterone $(19.0 \mathrm{ng} / \mathrm{dl})$ concentrations in his serum, compared to those of reported 17OHD cases $(0.3-5.0 \mathrm{ng} / \mathrm{dl}$ and $0.2-8.5 \mathrm{ng} / \mathrm{dl}$, respectively [2]), can be explained by the same concept. Slightly high DOC yielded to the inconspicuousness of hypertension and hypokalemia, which in turn caused aldosterone not to be suppressed.

Since latent GC deficiency may deteriorate into acute adrenal crisis under serious stress, correct diagnosis and proper management of latent GC deficiency are of vital importance. It may be advisable to exclude partial 17OHD in cases of delayed or incomplete pubertal development, even if symptoms of excess MC are absent.

The molecular basis of $17 \mathrm{OHD}$ has been well established. To date, 26 mutations of the CYP17 gene have been reported in patients of different ethnic backgrounds with $17 \mathrm{OHD}$, including missense mutations, nonsense mutations, small deletions, and small insertions, and 2 splice site mutations [16-21 and references therein].

In our patient, direct sequencing, covering the entire coding regions and exon-intron boundaries, did not reveal any mutation of the $C Y P 17$ gene. All hitherto known mutations of the $C Y P 17$ gene have been shown to be in the coding regions and splicing sites of the introns. Nevertheless, it should be emphasized that most molecular investigations of the CYP 17 gene have dealt with patients with the complete form of $17 \mathrm{OHD}$, and analysis of the partial form of $17 \mathrm{OHD}$ is limited [5, 22]. Consequently, the presence or absence of mutation(s) in the intron or promoter/enhancer regions of the CYP17 gene should be pursued in our patient, as well as in other patients with partial 17OHD.

It is more tempting to postulate the hypothesis that 17OHD in our patient was caused by a defect in a hitherto unknown gene, not of the CYPI7 gene, although this is highly speculative. The presumed gene aberration may impair the function of a transcription factor that binds to the regulatory sequence of the CYP17 gene. In this regard, the skeletal malformations (the SGS phenotype) in our patient are of substantial interest because the $17 \mathrm{OHD}$ and the SGS phenotype in our patient may be causally related to one another.

SGS is a rare constitutional bone disease, characterized by the combination of marfanoid habitus with craniosynostosis [23-25]. SGS may be an allelic disorder of Marfan syndrome, because mutations of the fibrillin-1 gene (assigned to 15q21.1) have been recently reported in some patients with SGS [26], although it remains inconclusive whether the mutations are disease-causing [27]. To date, no association with 17OHD has been reported in either SGS or Marfan syndrome, and the concurrence of $17 \mathrm{OHD}$ with the SGS phenotype in our patient may be for- 
tuitous. But, it is conceivable that SGS is genetically heterogeneous, and in this respect there is a suggestive report regarding a relationship between $18 \mathrm{q}$ deletion syndrome and 17,20-lyase deficiency [28]. The authors demonstrated the absence of 17,20-lyase activity in testicular tissue from a child with $18 \mathrm{q}$ deletion syndrome. They also found low DHEA-sulfate levels in other six patients with $18 \mathrm{q}$ deletion, and speculated that regulatory components of 17,20-lyase may be located on chromosome 18 , distal to band q21. Since the clinical symptoms of $18 \mathrm{q}$ deletion and those of our patient overlap each other (microcephaly, ear anomalies, and arachnodactyly), it may be that our patient has a submicroscopic deletion in the 18q region.

Consequently, the unusual clinical constellation of our patient, comprising the partial form of combined 17OHD and a mild SGS phenotype, may be the result of a mutation of a novel regulator gene that controls both $17 \alpha$-hydroxylation/17,20-lyase activities and skeletal morphonogenesis, which may be located in the $18 \mathrm{q}$ region.

\section{Conclusion}

A case of partial 17OHD is reported. The endocrinological characteristics were unusual latent GC deficiency without MC excess, as well as delayed puberty, and the patient had generalized skeletal changes. The molecular basis of this case remains unknown, and further research is needed for clarification.

\section{Acknowledgment}

The authors wish to thank Dr. T. Hasegawa, Dr. S. Satoh, and Dr. T. Ogata (Dept. of Pediatrics, Keio University, Tokyo) for valuable advice and discussion regarding the diagnosis of the patient. We are indebted to Dr. K. Fujieda and Dr. S. Abe (Dept. of Pediatrics, Hokkaido University, Sapporo) for providing convenience of CYP17 sequencing procedure.

\section{References}

1. Yanase T, Simpson ER, Waterman MR (1991) $17 \alpha-$ hydroxylase/17,20-lyase deficiency: From clinical investigation to molecular definition. Endocr Rev 12: 91-108.

2. Kater CE, Biglieri EG (1994) Disorders of steroid $17 \alpha$ hydroxylase deficiency. Endocrinol Metab Clin North Am 23: 341-357.

3. Bosson D, Wolter R, Toppet M, Franckson JRM, de Peretti E, Forest MG (1988) Partial 17,20-desmolase and $17 \alpha$-hydroxylase deficiencies in a 16 -year-old boy. $J$ Endocrinol Invest 11: 527-533.

4. de Lange WE, Doorenbos H (1990) Incomplete virilization and subclinical mineralocorticoid excess in a boy with partial 17,20-desmolase/17 $\alpha$-hydroxylase deficiency. Acta Endocrinol (Copenh) 122: 263-266.

5. Ahlgren R, Yanase T, Simpson ER, Winter JSD, Waterman MR (1992) Compound heterozygous mutations (Arg $239 \rightarrow$ Stop, Pro $342 \rightarrow$ Thr) in the CYP17 (P45017 $\alpha$ ) gene lead to ambiguous external genitalia in a male patient with partial combined $17 \alpha$-hydroxylase/ 17,20-lyase deficiency. J Clin Endocrinol Metab 74: 667-672.

6. Monno S, Ogawa H, Date T, Fujioka M, Miller WL, Kobayashi M (1993) Mutation of histidine 373 to leucine in cytochrome $\mathrm{P} 450 \mathrm{c} 17$ causes $17 \alpha$-hydrokylase deficiency. J Biol Chem 268: 25811-25817.

7. Picado-Leonard J, Miller WL (1987) Cloning and sequence of the human gene for P450c17 (steroid $17 \alpha$-hydroxylase/17,20 lyase): Similarity with the gene for P450c21. DNA 6: 439-448.

8. Kagimoto M, Winter JSD, Kagimoto K, Simpson ER, Waterman MR (1988) Structural characterization of normal and mutant human steroid $17 \alpha$-hydroxylase genes: molecular basis of one example of combined $17 \alpha$ hydroxylase/17,20 lyase deficiency. Mol Endocrinol 2: 564-570.

9. Peterson RE, Imperato-McGinley J, Gautier T, Shackleton C (1985) Male pseudohermaphroditism due to multiple defects in steorid-biosynthetic microsomal mixedfunction oxidases. A new variant of congenital adrenal hyperplasia. N Engl J Med 313: 1182-1191.

10. Kagawa J, Tanae A, Hashimoto N, Tanaka T, Hibi I, Kominami S (1988) A new variant of congenital adrenal hyperplasia $(\mathrm{CAH})$ with combined deficiencies of $17 \alpha$ hydroxylase, 17,20 desmolase and 21-hydroxylase. Acta Paediatr Jpn 30 (suppl): 239-242.

11. Malunowicz E, Romer TE, Szarras-Czapnik M, Mielniczuk Z, Gajewska D (1987) Combined deficiency of $17 \alpha$ hydroxylase and 21-hydroxylase in an 8 year old girl. Endokrynol Pol 38: 117-124.

12. Miller WL (1988) Molecular biology of steroid hormone synthesis. Endocr Rev 9: 295-318.

13. Abad L, Parrilla JJ, Marcos J, Gimeno F, Bernal AL 
(1980) Male pseudohermaphroditism with $17 \alpha$ hydroxylase deficiency. A case report. $\mathrm{Br} J$ Obstet Gynaecol 87: 1162-1165.

14. Heremans GFP, Moolenaar AJ, Van Gelderen HH (1976) Female phenotype in a male child due to 17- $\alpha$ hydroxylase deficiency. Arch Dis Child 54: 721-723.

15. Roberts CM, Adams PW, Lilford RJ (1985) Complete steroid 17 alpha hydroxylase deficiency in an XY patient presenting as primary amenorrhoea and low body weight. Pediatr Adolescent Gynecol 3: 183-204.

16. Yanase T (1995) $17 \alpha$-hydroxylase/17,20-lyase defects. J Steroid Biochem Molec Biol 53: 153-157.

17. Oshiro C, Takasu N, Wakugami T, Komiya I, Yamada T, Eguchi Y, Takei H (1995) Seventeen $\alpha$ hydroxylase deficiency with one base pair deletion of the cytochrome P450c17 (CYP17) gene. J Clin Endocrinol Metab 80: 2526-2529.

18. Geller DH, Mendonça BB, Miller WL (1996) The molecular basis of isolated 17,20 lyase deficiency. Pediatr Res 39: 89A.

19. Laflamme N, Leblanc JF, Mailloux J, Faure N, Labrie F, Simard J (1996) Mutation R96W in cytochrome $\mathrm{P} 450 \mathrm{c} 17$ gene causes combined $17 \alpha$ hydroxylase/17-20-lyase deficiency in two French Canadian patients. J Clin Endocrinol Metab 81: 264268.

20. Suzuki $Y$, Nagashima $T$, Nomura $Y$, Onigata $K$, Nagashima K, Morikawa A (1998) A new compound heterozygous mutation (W17X, 436 $+5 \mathrm{G} \rightarrow \mathrm{T}$ ) in the cytochrome $\mathrm{P} 450 \mathrm{c} 17$ gene causes $17 \alpha$-hydroxylase/ 17,20-lyase deficiency. J Clin Endocrinol Metab 83: 199-202.

21. Yamaguchi H, Nakazato M, Miyazato M, Kangawa K, Matsukura S (1997) A 5'-splice site mutation in the cytochrome P450 steroid $17 \alpha$-hydroxylase gene in $17 \alpha$-hydroxylase deficiency. J Clin Endocrinol Metab 82: 1934-1938.

22. Yanase T, Kagimoto M, Suzuki S, Hashiba K, Simpson ER, Waterman MR (1989) Deletion of a phenylalanine in the N-terminal region of human cytochrome $\mathrm{P} 45017 \alpha$ results in partial combined $17 \alpha$ hydroxylase/17,20-lyase deficiency. J Biol Chem 264: 18076-18082.

23. Shprintzen RJ, Goldberg RB (1982) A recurrent pattern syndrome of craniosynostosis associated with arachnodactyly and abdominal hernias. $J$ Craniofac Genet Dev Biol 2: 65-74.

24. Adès LC, Morris LL, Power RG, Wilson M, Haan EA, Bateman JF, Milewicz DM, Sillence DO (1995) Distinct skeletal abnormalities in four girls with Shprintzen-Goldberg syndrome. Am J Med Genet 57: 565-572.

25. Nishimura G, Nagai T (1996) Radiographic findings in Shprintzen-Goldberg syndrome. Pediatr Radiol 26: 775-778.

26. Sood S, Eldadah ZA, Krause WL, McIntosh I, Dietz HC (1996) Mutation in fibrillin-1 and the Marfanoidcraniosynostosis (Shprintzen-Goldberg) syndrome. (letter) Nature Genet 12: 209-211.

27. Watanabe Y, Yano S, Koga Y, Yukizane S, Nishiyori A, Yoshino M, Kato H, Ogata T, Adachi M (1997) P1148A in fibrillin-1 is not a mutation leading to Shprintzen-Goldberg syndrome. (letter) Hum Mutat 10: 326-327.

28. Chasalow FI, Blethen SL, Knight SM, Taysi K (1986) 18q deletion syndrome in a child with steroid-17,20lyase deficiency. Steroids 47: 421-429. 